\title{
Formação do Profissional Médico: a Aprendizagem na Atenção Básica de Saúde
}

PALAVRAS-CHAVE:

- Educação Médica;

- Prática Profissional;

- Ensino;

- Aprendizagem;

- Estudantes de Medicina.

KEY-WORDS:

- Education, Medical ;

- Professional Practice;

- Teaching;

- Learning;

- Students, Medical.

Recebido em: 13/12/2005

Aprovado em: 13/02/2007

\section{Medical Education: Learning with Primary Care}

Ricardo Corrêa Ferreira ${ }^{1}$ Roseli Ferreira da Silva ${ }^{1}$ Cristiane Biscaino Aguer ${ }^{1}$

\begin{abstract}
RESUMO
Os processos de formação dos profissionais de saúde vêm passando por transformações. Neste contexto, a Faculdade de Medicina de Marília (Famema) implementou um currículo integrado, utilizando em sua metodologia de ensino a diversificação de cenários de aprendizagem. Analisou-se, nesta pesquisa científica, a percepção dos acadêmicos de Medicina das primeira e segunda séries sobre as ações em saúde que desenvolvem com a comunidade na Unidade Educacional de Prática Profissional (UPP) no cenário da Atenção Básica de Saúde (ABS). A abordagem qualitativa foi a opção de análise desta investigação, que permitiu construir quatro categorias empíricas comuns às duas séries: a construção do conhecimento no cotidiano das ações de saúde; a contribuição social do estudante; o aprimoramento das relações e o olhar para as diversidades. Além disso, há duas categorias referentes à segunda série: a formação de um novo olhar sobre o SUS; e a ampliação dos cuidados a partir de necessidades de saúde. Evidenciam-se, então, percepções comuns entre ambas as séries do curso médico em relação à aprendizagem na $A B S$, mostrando a importância que este cenário tem na formação médica diferenciada, notadamente na construção de sujeitos críticos e reflexivos, capazes de aprender a aprender com a realidade na qual se inserem.
\end{abstract}

\begin{abstract}
The processes of medical education are undergoing transformations. In this context, the Faculty of Medicine of Marilia (FAMEMA) implemented an integrated curriculum, using in its teaching methodology the diversification of learning sceneries. In this study we analyzed the perceptions of first and second year medical students on the health actions they provide to the community in the field of Primary Care (PC), in the Educational Unit for Professional Practice. The research method chosen for this investigation was a qualitative approach that allowed constructing four empiric categories common to the two years: the construction of knowledge based on the daily routine of the health actions; the social contribution of the student; the improvement of relationships and the attention to diversities. Furthermore, there are two categories specific to the second year: creation of a new understanding of the Unified Health System (SUS) and the amplification of care actions according to health needs. It can be observed that the students of both years of the medical course have common perceptions on the learning process in the field of primary care, showing the importance of this scenery for a differentiated medical education, above all for the construction of critical and reflexive professionals capable of learning how to learn with the reality they are facing.
\end{abstract}




\section{INTRODUÇÃO}

Para enfrentar os desafios do futuro é necessário atribuir novos objetivos à educação em saúde, e uma nova concepção ampliada de educação deveria "fazer com que todos pudessem descobrir, reanimar e fortalecer o seu potencial criativo, e isto supõe que se ultrapasse a visão puramente instrumental da educação, considerada como a via obrigatória para obter certos resultados, e se passe a considerá-la em toda a sua plenitude: realização da pessoa que, na sua totalidade, aprende a ser"1.

Entre os usuários, gestores e profissionais da área da saúde se observa, ainda, uma concepção de atenção à saúde centrada no atendimento individual e curativo, hospitalocêntrico e de tecnologias sofisticadas, contudo, que não tem resolvido efetivamente as demandas e as necessidades da população².

Outro ponto a destacar nos processos de formação desses profissionais é a pouca valorização da formação generalista. No caso da Medicina, nos últimos anos desenvolveram-se inúmeras especialidades médicas, o que provocou um impacto devastador na organização de sua prática, fragmentando o cuidado à saúde; e, ainda na graduação, cada vez mais as especialidades foram incorporadas aos currículos, multiplicando-se disciplinas, conteúdos e tempos. Perdeu-se, assim, o conhecimento generalista das ações em saúde, e substituiu-se cada vez mais o subjetivismo da relação médico-paciente pelo objetivismo tecnológico dos exames complementares de diagnóstico ${ }^{2}$.

No currículo tradicional do curso médico ocorre a segregação entre teoria e prática, e a fragmentação do aprendizado, que favorece o crescimento das especializações existentes, vendo-se conteúdos sem relevância, que hierarquizam e desintegram o conhecimento. Observa-se, também, enorme resistência às mudanças nas universidades no que diz respeito à "des-hospitalização" do processo de ensino-aprendizagem. Diversificar os cenários de aprendizagem, "saindo" do hospital e trabalhando com outras situações, representa um grande desafio para a educação médica. Soma-se a isso o fato de os graduandos em Medicina resistirem a atuar em cenários que se distanciam dos ideais que cultivam - ser um especialista em um hospital privado de alto nível ou trabalhar em consultório próprio ${ }^{3}$.

Em meio a este contexto de (de)formações e necessidades de saúde, Piancastelli ${ }^{2}$ evidencia a necessidade de mudança nos currículos dos cursos da área de saúde, com conceitos e práticas relacionados ao planejamento, promoção de saúde e prevenção de doenças, utilizando-se tecnologias eficazes e metodologias de ensino-aprendizagem que vão além dos espaços acadêmicos, a fim de chegar às necessidades de saúde da população.
Objetivam-se, então, nos currículos da área da saúde, novos rumos para a educação, e esta, segundo Delors et al.1, deve ter uma concepção diferenciada e organizada em torno de quatro aprendizagens fundamentais que, ao longo da vida, seriam para cada indivíduo os pilares do conhecimento:

"Aprender a conhecer, levando em conta as rápidas alterações provocadas pelo progresso científico e as novas formas de atividade econômica e social, há que conciliar uma cultura geral suficientemente vasta, com a possibilidade de dominar, profundamente, um reduzido número de assuntos. Esta cultura geral constitui, de certa maneira, o passaporte para uma educação permanente, na medida em que fornece o gosto e as bases para a aprendizagem ao longo de toda a vida.

Aprender a fazer, a fim de adquirir, não somente uma qualificação profissional, mas, de uma maneira mais ampla, competências que tornem a pessoa apta a enfrentar numerosas situações e a trabalhar em equipe.

Aprender a ser, para melhor desenvolver a sua personalidade e estar à altura de agir com cada vez maior capacidade de autonomia, de discernimento e de responsabilidade pessoal. Para isso, não negligenciar na educação nenhuma das potencialidades de cada indivíduo: memória, raciocínio, sentido estético, capacidades físicas, aptidão para comunicar-se.

Aprender a viver juntos, desenvolvendo o conhecimento acerca dos outros, da história, tradições e espiritualidade. E a partir daí, criar um espírito novo que, graças precisamente a esta percepção das nossas crescentes interdependências, graças a uma análise partilhada dos riscos e dos desafios do futuro, conduza à realização de projetos comuns e preparar-se para gerir conflitos".

Nesta perspectiva, aprender se torna para o estudante, segundo Freire ${ }^{4}$, uma aventura criadora, algo que por isso mesmo se torna muito mais rico do que a mera repetição da lição dada. Assim, aprender é construir, reconstruir, constatar para intervir e mudar, para, neste "passeio" pela aprendizagem, o estudante ir-se tornando sujeito crítico, epistemologicamente curioso, que constrói o conhecimento partindo da problematização do objeto e participando de sua construção. E, ainda segundo o autor, trata-se da "capacidade de aprender, não apenas para adaptarmos à realidade, mas, sobretudo, para transformar, para nela intervir, recriando-a".

Portanto, é na formação profissional centrada em cenários hospitalares, na qual se desenvolvem os currículos médicos, que a formação médica ampliada, humanista e generalista não tem sido eficazmente estimulada, tampouco caracteri- 
zando cenários que formam sujeitos crítico-reflexivos. Necessita-se, então, além das mudanças pedagógica e metodológica na formação do profissional em saúde, diversificar os cenários de ensino-aprendizagem na construção destes novos currículos e sujeitos 5 .

\section{DIVERSIFICAÇÃO DOS CENÁRIOS DE ENSINO- APRENDIZAGEM}

A diversificação dos cenários é compreendida como uma das estratégias para a transformação curricular. Essa estratégia aproxima os estudantes da vida cotidiana das pessoas e desenvolve olhares acadêmicos críticos e voltados para os problemas reais da população.

Cenários de aprendizagem não devem se restringir a locais de desenvolvimento de práticas profissionais como espaços físicos de trabalho, mas, sim, representar espaços em que as relações dos sujeitos sejam eficazmente desenvolvidas. Espaços estes que possibilitem a incorporação do estudante ao processo de produção do serviço e gerem mudanças no processo de formação profissional do estudante ${ }^{6}$.

Uma das opções dessa diversificação é a aprendizagem baseada na comunidade, na qual o estudante permanece durante sua formação inserido num processo dinâmico de práticas integradas à comunidade, produzindo conhecimento e serviço de saúde para a população. Esse tipo de educação requer envolvimento dos educandos com a comunidade, fazendo-se reflexões acerca das práticas em saúde envolvidas para a construção de sua aprendizagem, diferentemente dos processos de formação que envolvem breves estágios em centros de saúde-escola7.

\section{A FAMEMA E SUA PROPOSTA DE FORMAÇÃO INOVADORA}

Construiu-se, então, em 2003, a Unidade Educacional de Prática Profissional (UPP) no currículo inovador implementado na Faculdade de Medicina de Marília (Famema). Nesta perspectiva, os estudantes das duas primeiras séries de Medicina são motivados a se comunicarem claramente e a desenvolverem capacidades para um adequado trabalho em equipe na Atenção Básica de Saúde (ABS), satisfazendo as necessidades de saúde das pessoas, das famílias e da comunidade. Eles participam da exploração de problemas e situações, trazendo conhecimentos prévios (valores, representações, experiências) para nortear suas aprendizagens ${ }^{8}$.

Ainda segundo a proposta, os acadêmicos buscam informações e as analisam criticamente, e, então, as articulam e aplicam em sua formação profissional. Constrói-se, assim, um currículo inovador, em que a aprendizagem é individualizada e tem como objetivo estimular o estudante a desenvolver a capacidade de aprender a aprender.

Com isso, o currículo emancipa o processo de ensinoaprendizagem e é entendido como uma práxis apoiada nos seguintes princípios: na prática sustentada pela reflexão sobre a práxis, fazendo interagirem reflexão e atuação; na prática que se relaciona às interações do mundo social e cultural; e na prática que converte estudantes em elaboradores de seu próprio saber. Desta forma, refere-se a um currículo compromissado com a realidade ${ }^{9}$.

Proporciona-se, com essa aprendizagem, um processo de crescimento e desenvolvimento da pessoa em sua totalidade, englobando três grandes áreas de aprendizagem: conhecimento, habilidades e atitudes ou valores ${ }^{10}$.

E é a área de atitudes e valores, tão "esquecida" nos currículos atuais, que tem seu lugar privilegiado na UPP. Segundo Maseto ${ }^{10}$, esta compreende o desenvolvimento de valores pessoais, como responsabilidade por seu processo de aprender através de significados, ética, respeito ao outro e a suas opiniões, criticidade, autonomia, criatividade, desenvolvimento de valores cidadãos e políticos, como a não limitação a soluções técnicas dos problemas de sua área, analisando-os à luz das ciências ambientais, como a Antropologia e a Sociologia, comprometendo-se, portanto, com o crescimento e a melhoria da qualidade de vida da população a que serve, construindo valores éticos, históricos, sociais e culturais.

Diante desta perspectiva, a UPP objetiva, dentro do plano curricular da Famema, enfrentar os desafios inerentes à formação dos profissionais de saúde, utilizando cenários de prática-aprendizagem diversificados e condizentes com as situações reais vivenciadas pela comunidade mariliense. Logo, ao se utilizar a situação de serviço - Unidade de Saúde da Família (USF) -, propicia-se aos estudantes de Medicina, já nas primeiras séries da Famema, a instrumentalização necessária à integralidade de sua aprendizagem.

Constrói-se, assim, a interação do aprendiz com o mundo social, o seu situar histórico no contexto e espaço da sociedade, visando ao comprometimento com seu desenvolvimento na ABS. Vivem-se práticas sociais e intercâmbios que induzem à solidariedade, à colaboração, à experimentação, a relações com o conhecimento e a cultura que estimulam a busca, o contraste, a crítica e a criação ${ }^{10}$.

\section{OBJETIVO}

Analisar a percepção dos acadêmicos da primeira e segunda séries de Medicina sobre as ações em saúde que desenvolvem com a comunidade mariliense, no contexto da Atenção Básica de Saúde (ABS), na Unidade Educacional de Prática 
Profissional (UPP), parte do novo currículo da Famema a partir de 2003.

\section{METODOLOGIA}

Esta investigação se desenvolveu por meio de um estudo qualitativo sobre a percepção dos estudantes de Medicina da primeira e segunda séries da Famema em relação às atividades desenvolvidas na UPP. Acredita-se que a análise de atitudes, motivações, expectativas e valores destes estudantes perante a UPP será mais bem compreendida a partir de uma abordagem qualitativa ${ }^{11}$. Este tipo de estudo também compreende e classifica processos dinâmicos vividos por grupos sociais e contribui no processo de mudança e entendimento do comportamento dos indivíduos, envolve interesse maior pelo cotidiano do que por fatos isolados, além de ter maior utilização de significados em detrimento da freqüência de fatos. Desta forma, dá-se ênfase ao desenvolvimento da percepção dos estudantes ${ }^{12}$.

\section{População e Sujeitos}

O universo desta investigação conta com 160 estudantes. Para a coleta de dados, foram incluídos 20 estudantes escolhidos de forma aleatória e representativa, mediante seleção por sorteio de um estudante de Medicina de cada um dos 20 grupos da UPP da primeira e segunda séries. Os sujeitos, os 20 estudantes, foram separados por série para a coleta de dados.

\section{Aspectos Éticos e Procedimento de Coleta}

Esta pesquisa, atendendo aos procedimentos previstos na Resolução 196/96 do Conselho Nacional de Saúde, foi aprovada pelo Comitê de Ética em pesquisa da instituição em que foi desenvolvida, acrescentando-se, ainda, que não houve qualquer conflito de interesse dos autores.

Na coleta dos dados foi utilizada a técnica de grupo focal, que consiste numa entrevista em grupo, baseada em um tópico a ser explorado. Nesta investigação foram utilizados dois grupos focais: um composto por dez estudantes da primeira série de Medicina, e outro por dez estudantes da segunda série de Medicina. Após a concordância na participação, os acadêmicos assinaram o termo de consentimento livre e esclarecido. Foram utilizadas perguntas norteadoras na discussão, as quais envolveram a percepção dos estudantes nas atividades e ações em saúde com a comunidade mariliense na UPP. As perguntas norteadoras foram as seguintes: a) Fale sobre as atividades que vocês realizam na UPP; b) O que significam para vocês estas atividades?; c) Quais as atividades que vocês realizaram com a comunidade esta semana na ABS, e o que estas representam para vocês?

\section{Forma de Análise dos Resultados}

$\mathrm{Na}$ análise dos dados foi utilizada a técnica de análise de conteúdo, a qual, segundo Bardin"13,é "uma técnica de investigação que, através de uma descrição objetiva, sistemática e quantitativa do conteúdo manifesto das comunicações, tem por finalidade a interpretação destas mesmas comunicações". Foi realizada uma leitura das transcrições das falas dos participantes dos grupos focais, desmembradas em unidades de registro. Ou seja, foi feita uma codificação, que corresponde a uma transformação dos dados brutos do texto para que se conseguisse atingir uma representação do conteúdo visando à categorização. Cada estudante foi representado por E (E1, E2... E10) e separado em M1 (primeira série de Medicina) e M2 (segunda série de Medicina).

\section{RESULTADOS}

A análise dos dados permitiu construir quatro categorias empíricas comuns às duas séries: a construção do conhecimento no cotidiano das ações de saúde; a contribuição social do estudante; o aprimoramento das relações; o olhar para as diversidades. Além disso, há duas categorias referentes à segunda série: a formação de um novo olhar sobre o SUS e a ampliação dos cuidados a partir de necessidades de saúde.

As categorias empíricas construídas neste estudo permitem compreender a capacidade transformadora que a UPP propicia aos estudantes de Medicina da Famema, uma vez que eles atuam num contexto real da prática profissional, como a ABS, e se relacionam com as pessoas da comunidade, desenvolvendo uma formação profissional construtora de seus saberes críticos, reflexivos e significativos. Cada uma das categorias será abordada a seguir.

\section{A Construção do Conhecimento no Cotidiano das Ações de Saúde}

Por meio das falas dos sujeitos, observa-se que a prática é um elemento motivador para a construção do conhecimento. Os estudantes passam a entender o lugar da prática na configuração de novos saberes. Ao desenvolverem as ações de saúde na ABS e se confrontarem com os problemas em tempo real, os estudantes reconhecem uma nova concepção de aprendizagem, na qual utilizam capacidades prévias e buscam novos conhecimentos (cognitivos, afetivos e psicomotores) para enfrentar as situações que emergem do cotidiano, construindo, assim, maior significado em sua aprendizagem e possibilitando a construção de novos saberes. Contrapõem-se, portanto, à perspectiva de que uma sólida base científica deve anteceder a prática, ou seja, de que a teoria deva anteceder a prática. 
[...] eu acho que esse aprendizado mexe com a gente porque tem o aprendizado que você lê no livro, mas que não tem o significado que mexe com você e é meramente uma passagem de livro. Agora se existe uma coisa que mexe com você, que toca profundo os seus sentimentos, esse é realmente um aprendizado que vale a pena.(E2M2) [...] você vai estudar porque chama a atenção o que é importante para você, então fica gravado e retido como aprendizagem. Você fica muito inseguro porque não tem uma aprendizagem antes, mas quando ela vem, você percebe. (E2M1)

[...] lá é o lugar para aprender a trabalhar com a comunidade... coletamos dados para a clínica, para ver não só o biológico, mas os detalhes sociais... e indo na casa da pessoas, você começa a enxergar desde o começo, para ter uma visão do paciente mais integrada [...]. (E3M1)

[...] você vai ter um contato com os problemas e depois vai pensar no que pode fazer, isso é fundamental, é claro que seria mais fácil, mais prático se te dessem uma cartilha com perguntas e respostas possíveis [...] mas aprendemos muito mais assim. A experiência fica para o resto da vida. (E2M1)

Os estudantes revelam que a aprendizagem é construída não só pela dimensão "tecnicista", pelos procedimentos ou conteúdos temáticos; mostram que, ao se relacionarem com as pessoas na comunidade, estão construindo seu próprio conhecimento de forma integrada, pois reúnem atributos cognitivos, afetivos e psicomotores, e articulam os conhecimentos de diversos campos do saber (ciências humanas e biológicas) necessários à prática médica. Estão aprendendo a levar em conta a realidade social como princípio norteador em seu atendimento humano e de qualidade aos indivíduos.

[...] só o fato de você andar na rua e as pessoas te conhecerem e falar: oi, tudo bem?, é muitíssimo mais significativo do que um fato biológico isolado que foi o máximo. (E1M2)

[...] eu vou ter mais sensibilidade para estar percebendo as coisas, tentar resolver mais as situações, pois sei que quero enfrentar uma situação para saber como devo agir posteriormente. (E2M1)

[...] vou atrás, vou aprender também o biológico... e ajudo as pessoas com indicações, medicações... vamos na casa da pessoa... ela fala dos problemas dela... e tentamos fazer com que ela tenha uma adesão ao tratamento [...]. (E5M1)

[...] é difícil saber o que é pessoal, o que é profissional... porque quando você está trabalhando, você está mexendo com o seu pessoal, não tem como você desvincular e acho que o pessoal ajuda você a ver algumas coisas do profissional [...].(E2M1)

\section{A Contribuição Social do Estudante}

Os discursos dos sujeitos evidenciam o papel social que eles têm nas relações com a comunidade, formando um elo entre o estudante, o serviço de saúde e a população na ABS. Essa relação contribui para a melhoria das condições de saúde das pessoas, ao mesmo tempo em que colabora para a aprendizagem do estudante. Reconhecem os saberes um do outro na medida em que ocorre a troca de experiências que geram ajudas mútuas, estudante-comunidade. Os sujeitos afirmam o compromisso que devem assumir ao cuidarem das pessoas, envolvendo-se com estas nas relações de saúde que desempenham; ilustram com sua contribuição, ajudam as pessoas a se tornarem mais independentes de seu cuidado (autocuidado) e a se conscientizarem dos direitos e deveres sociais. Além disso, relatam a autonomia adquirida pelas pessoas da comunidade quando as auxiliam a compreender as relações sociais.

[...] a gente tem a oportunidade excepcional de estar tendo contato com essas famílias e a troca é muito grande, pois não é só a gente que ajuda eles, eles ajudam muito a gente, até porque numa Faculdade de Medicina as pessoas têm o afastamento da comunidade e só ficam no hospital, tendo um distanciamento da realidade das pessoas. (E1M2)

[...] é importante a experiência de poder transmitir algum conhecimento, e não só cumprir o papel de estudante da área de saúde, mas cumprir um papel de próprio cidadão mesmo, exercendo seu papel social [...]. (E2M2)

[...] é legal a gente ir lá (na comunidade), a gente aprender a ajudar as pessoas para que elas possam se virar sozinhas [...]. (E3M1)

Eu acho que eu aprendi mais a ajudar as pessoas, eu acho que [...] consegui trazer as pessoas para o social, e isso [...] para mim foi muito bom. (E7M1)

Existe um envolvimento emocional, em que você se dedica, e procura fazer o melhor que pode para aquelas pessoas, então, isso é também um pré-requisito para estar aqui fazendo Medicina [...], você tem compromisso, procura ajudar o melhor que pode [...].(E8M2)

\section{O Aprimoramento das Relações}

Os estudantes reconhecem que o trabalho com a comunidade favorece o desenvolvimento das relações interpessoais, que são essenciais para sua formação. Podemos observar uma qualificação da relação estudante-paciente, questão diretamente relacionada à humanização da atenção. Os estudantes tam- 
bém evidenciam o desenvolvimento de habilidades de comunicação como potencializadoras destas relações.

[...] acho que hierarquia segrega porque ficam profissionais de saúde lá em cima e a comunidade lá embaixo [...]. Acho que não pode ser assim, tem que haver troca na relação do profissional de saúde com a comunidade. Creio que a comunidade ensina para o médico muito mais do que médico acaba passando para ela [...]. (E1M2)

[...] conforme eu ajudo ela (a comunidade), ela me ajuda [...] com relacionamento humano, como lidar com pacientes, aprendi a lidar com as pessoas, encarar e abordá-las [...]. (E5M1) [...] é engraçado você passar pelas pessoas e ver como muda a receptividade delas, por exemplo, tem uma gestante de 16 anos [...] que a gente respeita o jeito dela ser: ela não gosta de falar e eu falo demais, então a gente se equilibra [...] acho que se não fosse o trabalho da UPP iria demorar um pouco para percebermos isso [...] a gente aprende com a prática. (E1M1)

[...] a gente fica acanhado de começar a falar (em uma visita domiciliária, mas aos poucos a gente tem aprendido a falar. (E3M1)

Eu aprendi a escutar os velhinhos, não que eu não escutasse, mas que é muito interessante e foi legal [...]. As pessoas idosas precisam muito da gente. (E1M1)

O trabalho com a comunidade desenvolvido pelos estudantes na ABS e esta forma de se relacionar com as pessoas da comunidade onde atuam têm possibilitado a construção de vínculos entre as pessoas-estudantes-profissionais de saúde, estabelecendo uma relação mais horizontal, menos autoritária e distante. A mudança na relação possibilita aos estudantes a construção de uma "nova" imagem do profissional médico perante a comunidade.

[...] quebrou aquela muralha que existe na mesa do médico. O paciente entra no consultório, vê a mesa e o médico do outro lado, a mesa é uma muralha imensa e essa muralha se quebra quando a gente vai na casa da pessoa [...] quebra uma distância muito grande que existe do profissional de saúde e paciente, onde ele conta coisas talvez que não contaria no consultório. (E1M2)

[...] acredito que sempre há envolvimento quando você tem relação entre seres humanos, é impossível não ter relações de envolvimento entre seres humanos. Não interessa se são boas ou se são ruins, o que interessa é que há envolvimento. (E3M2)

[...] quando chegar um paciente no consultório (depois de formado) a gente não vai tratar a doença, mas sim pessoas, seres humanos [...]. (E1M2)
[...] tem o caso que eu acompanhei desde o começo do ano e ele teve pé diabético [...] sofreu várias amputações [...] e ele está melhor, mas o vínculo foi tão forte que ele fez a questão de fazer um churrasco para a gente de tão grato que ficou por termos acompanhado a cirurgia, a consulta ambulatorial [...] o vínculo foi impressionante, foi muito legal ter tido esse retorno. (E7M2)

Eu tive um paciente que nunca tinha falado num determinado assunto com nenhum outro profissional e ele falou justamente para mim e foi uma coisa que mexeu comigo, era forte e foi para mim que ele contou, foi gratificante, pois ele levou em consideração a empatia que teve comigo, o vínculo que tive com a família. Foi importante na vaidade profissional, pois ajuda a sermos profissionais melhores, diferentes e a ajudar de uma maneira diferente as pessoas [...]. (E10M2)

[...] pelo menos aquela pessoa que a gente esteve junto vai enxergar a profissão de Medicina de maneira diferente, porque eles sentem falta da gente ir na casa deles e, apesar de sermos estudantes, os pacientes acabam olhando para a gente de forma diferente, preocupando-se se a gente vai aquele dia nas suas casas [...]. (E6M2)

[...] tem pessoas que querem ir ao médico somente quando estão muito doentes, daí você tem que ir nas casas das pessoas com mais tempo, aumentar o vínculo com a pessoa. (E4M1)

\section{O Olhar para as Diversidades}

As falas dos estudantes evidenciam o respeito às características individuais, sociais e culturais da comunidade, mostram a valorização do outro na relação do cuidado. Os estudantes reconhecem a importância de interagir com as diferentes realidades, por meio das quais vão construindo habilidades e atitudes para o enfrentamento do novo, do desconhecido, ao realizarem o cuidado à saúde. Esta aprendizagem, que reposiciona a dimensão da prática, que traz a ação e a reflexão como elementos fundamentais para a aprendizagem, é percebida pelos estudantes como diferente da aprendizagem exclusiva nos livros.

[...] não fabricar juízo de valores, porque, por exemplo, tem muitas pessoas que reclamam da falta de dinheiro, que as coisas estão difíceis... aí depois ele fala que está terminando de pagar a prestação do vídeo [...] que vai comprar uma geladeira dúplex, então você pensa como é que pode? (E2M1)

[...] é complicado você mexer com coisas que são da pessoa, que é cultura dela, que são coisas que ela aprendeu durante a vida [...]. (E2M1) 
[...] tem um tiozinho que tem uma teoria sobre câncer [...] o câncer [...] é um verme que tem dentro de você e ele está dormindo [...] e ele trata toda a comunidade com os chazinhos [...] e a gente tem que aprender a lidar com isso [...] não tirar o chá da pessoa, mas acrescentar o remédio junto [...]. (E5M1)

Tem que se respeitar o espaço do outro... (E2M2)

[...] a única coisa que a gente teve de diferente deles foi oportunidade na vida [...].(E1M2)

[...] a gente tem que encarar as diferenças da realidade, estamos despreparados para um ambiente que não conhecemos [...].(E5M2)

[...] a UPP leva as diferenças sociais mais próximos da gente [...] em que vemos coisas da televisão na UPP, passo a passo [...] então você entra na casa de uma pessoa [...] o chão é de terra, ela tem cinco filhas, algumas já estão grávidas, nenhuma trabalha, e ela sustenta aquela casa com o salário mínimo e com a horta que ela tem na casa [...] sem contar o vocabulário, que é próprio deles [...].(E7M1)

[...] lá (na comunidade) nós temos um conhecimento real do meio social de baixas condições, e acredito que o maior aprendizado nisso é a gente estar na outra ponta da sociedade que não viveu [...]. (E1M2)

[...] a gente aprende a lidar com nossas próprias limitações [...] e a lidar com pessoas [...]. (E3M1)

\section{A Formação de um Novo Olhar sobre o SUS}

Os sujeitos evidenciam a necessidade de políticas públicas mais eficientes e a falta de integração das ações públicas. Os estudantes estão vivendo o SUS e ao mesmo tempo contribuindo para a qualificação e o fortalecimento da rede básica, em Marília, a partir do momento em que ampliam o olhar e procuram atender as necessidades de saúde dos indivíduos, famílias e comunidade.

[...] nós temos limites, o programa de saúde da família deveria ser exemplo para outras áreas públicas [...] temos limites na alfabetização, na política pública, na economia do bairro [...].(E1M2)

[...] educação e emprego, que é o básico, deveria ser fornecido não pelo sistema de saúde, mas pelo governo, através das escolas... contudo, é algo que até o posto de saúde tem feito, somando isso para ele, e será que este é o caminho certo? [...] será que o caminho certo não é cobrar de quem devia estar fazendo, o governo?, será que a gente não está mascarando uma realidade um pouco mais difícil? [...]. (E4M2)

[...] seria ideal se tivéssemos estudantes de economia, administração, ciências sociais, direito [...] estendendo os braços à comunidade $[\ldots]$, pois nós também temos limite de intervenção [...]. (E4M2)

\section{A Ampliação do Olhar sobre o Processo Saúde-Doença}

A percepção da realidade das pessoas, suas condições de vida, cultura e costumes permite ao estudante construir uma concepção do processo saúde-doença na qual compreendem os determinantes e as relações das doenças com o modo de vida e trabalho das pessoas. Essa concepção possibilita uma mudança no cuidado à saúde das pessoas, família e comunidade, que passa a ser um cuidado mais voltado para as ações de vigilância à saúde, o que leva à integralidade no cuidado do paciente.

[...] nessa vivência (UPP) acho que eu compreendi a importância de você tratar o paciente como um ser humano, que tem uma história de vida, e você tem que respeitar as limitações dele, seus hábitos de vida e eu tenho que usar isso para todos os pacientes que eu for atender [...]. (E7M2) [...] não adianta tentarmos resolver todos os problemas da população que não vamos conseguir. Eu sei que é um problema seríssimo emprego não só aqui, como no país inteiro, mas o que adianta a condição de enfermidade da pessoa se o emprego faz parte da saúde dela? [...]. (E7M2) [...] é realmente o conhecimento do que as pessoas vivem, porque se estamos em nosso consultório, estamos distantes da realidade delas, elas vêm até a gente, já na UPP a gente está indo até elas [...]. (E1M2)

Os estudantes diversificam o olhar para o cuidado às necessidades de saúde da população, ampliando as estratégias de intervenção para enfrentar as demandas da comunidade na ABS.

[...] ajudamos as famílias em suas necessidades de saúde, facilitando o acesso dessas aos serviços de saúde, agilizando e muitas vezes esclarecendo sobre o serviço de saúde, sobre suas necessidades de saúde [...]. (E1M2)

[...] tivemos a oportunidade de visitar várias vezes as pessoas e constatar mesmo que com o tratamento tinha havido melhora significativa na condição da saúde delas [...] ver que haviam melhorado [...]. (E2M2)

[...] e o que significa isso para nossa formação, nosso futuro, é que seremos profissionais diferenciados e, por mais especialistas que a gente seja, enxergaremos o paciente como um todo [...]. (E1M2)

[...] se você for em uma área muito pobre, vai ver que a origem das doenças das pessoas é basicamente a falta de educação, falta de conhecimento, higiene e falta de emprego [...]. (E6M2) 


\section{CONSIDERAÇÕES FINAIS}

Evidenciam-se percepções comuns entre os estudantes das duas primeiras séries que desenvolvem atividades no cenário da $\mathrm{ABS}$, notadamente em relação a seu próprio crescimento pessoal e profissional a partir dessa experiência.

A preocupação com uma prática integradora está presente nas situações vivenciadas pelos estudantes. Nelas ocorre concretamente a integração de conteúdos, sustentada pela ação-reflexão-ação dos atores dessa prática em um mundo real - uma construção social - que envolve conflitos, contradições, interações e problemas sociais, culturais e do trabalho. Os estudantes são agentes da elaboração de seu próprio conhecimento.

Reconhece-se o caráter social desta unidade educacional como currículo configurador da prática, uma vez que vem cumprindo o objetivo básico da socialização dos estudantes, que é prepará-los para a sua incorporação ao mundo do trabalho, pois estão desenvolvendo, além de conteúdos, idéias, habilidades, a formação de disposições, atitudes, interesses e comportamentos que compõem seu perfil profissional.

É certo que sua formação não se restringirá somente a este cenário de aprendizagem. Afinal, outros conhecimentos devem ser construídos pelo estudante ao longo de sua graduação. Contudo, este aprendizado no cenário da ABS, desde o início do curso, se diferencia do aprendizado de outros estudantes pelos vínculos que estabelecem, pela formação críticoreflexiva e pela capacidade que desenvolvem ao aprender a aprender com a realidade em que se inserem. Portanto, é primordial a inserção em cenários de práticas, como a ABS, no início do curso, para construir saberes condizentes com as reais necessidades de saúde da população.

Tem-se, então, como desafio incentivar novas experiências, como a da Famema, e a constante (re)construção da UPP, a fim de torná-la ainda mais responsável por processos de mudanças sociais, culturais e educacionais na formação dos profissionais médicos.

\section{REFERÊNCIAS}

1. Delors J, Mufti I, Amagi I, Carneiro R, Chung F, Geremek B, et al. Educação: um tesouro a descobrir: relatório para a UNESCO da comissão internacional sobre educação para o século XXI. 4⿳a ed. São Paulo: Cortez; 2000.

2. Piancastelli CH. Saúde da família e formação de profissionais de saúde. In: Arruda BKG, org. A educação profissional em saúde e a realidade social. Recife: Instituto Materno Infantil de Pernambuco,[IMIP]; 2001. p.121-40.
3. Feuerwerker LCM. Além do discurso de mudança na educação médica: processos e resultados. São Paulo: Hucitec; 2002.

4. Freire P. Pedagogia da autonomia: saberes necessários à prática educativa. 11aㅡ ed. Rio de Janeiro: Paz e Terra; 1999.

5. Feuerwerker LCM. A construção de sujeitos no processo de mudança da formação dos profissionais de saúde. Divulgação em Saúde para Debate 2000;22:18-24.

6. Feuerwerker L, Costa H, Rangel ML. Diversificação de cenários de ensino e trabalho sobre necessidades/problemas da comunidade. Divulgação em Saúde para Debate 2000;22:18-24.

7. Silva RF. Prática educativa transformadora: a trajetória da unidade educacional [dissertação]. São Paulo (SP): Faculdade de Saúde Pública da Universidade de São Paulo; 2000.

8. Faculdade de Medicina de Marília [Famema]. Avaliação da Unidade de Prática Profissional - $1^{\circ}$ semestre de 2003: estudantes de enfermagem e medicina. Marília: Faculdade de Medicina de Marília; 2004.

9. Gimeno Sacristán J. O currículo: uma reflexão sobre a prática. Porto Alegre: Artes Médicas; 1998.

10. Maseto MT. Discutindo o processo de ensino/aprendizagem no ensino superior. In: Marcondes E, Gonçalves EL, coordenador. Educação Médica. São Paulo: Sarvier; 1998. p. 11-9.

11. Richardson RJ. Pesquisa social: métodos e técnicas. São Paulo: Atlas; 1999.

12. Tobar F, Yalour MR. Como fazer teses em saúde pública: conselhos e idéias para formular projetos e redigir teses e informes de pesquisa. Rio de Janeiro: Fiocruz; 2001.

13. Bardin L. Análise de conteúdo. Lisboa: Persona; 1977.

\section{Conflito de Interesse}

Declarou não haver .

\section{Endereço para correspondência}

Ricardo Corrêa Ferreira

Rua 24, 425 - Centro

14790-000 - Guaíra - São Paulo

e-mail: riguaira@famema.br 
O nome correto da autora do artigo intitulado "Formação do profissional médico: a aprendizagem na atenção básica de saúde", publicado na Rev. Bras. Educ Med. 2007; 31(1), é CRISTIANE BISCAINO AGUERA.

A afiliação correta da professora Roseli Ferreira da Silva, autora do artigo intitulado "Formação do profissional médico: a aprendizagem na atenção básica de saúde", publicado na Rev. Bras. Educ Med. 2007; 31(1), é UNIVERSIDADE FEDERAL DE SÃO CARLOS, SÃO PAULO, BRASIL. 
O arquivo disponível sofreu correções conforme ERRATA publicada no Volume 31 Número 3 da revista. 